\title{
Electrokinetic remediation of diesel-contaminated silty sand under continuous and periodic voltage application
}

\author{
Gholamreza Asadollahfardi ${ }^{\dagger}$, Milad Rezaee \\ Civil Engineering Department, Technical and Engineering Faculty, Kharazmi University, Tehran 15614, Iran
}

\begin{abstract}
Hydrocarbon contamination is among the most challenging problems in soil remediation. Electrokinetic method can be a promising method to remediate hydrocarbon-contaminated soils. Electrokinetic method consists of different transport phenomena including electro-migration, electrophoresis, and electroosmotic flow. Electroosmotic flow is the main transport phenomenon for hydrocarbon removal in soil porous media. However, the main component of hydrocarbons is the hydrophobic organic which indicates low water solubility; therefore, it makes the electroosmotic flow less effective. The objective of the present study is to enhance electrokinetic remediation of diesel-contaminated silty sand by increasing the solubility of the hydrocarbons in the soil and then increase the efficiency. For this purpose, sodium dodecyl sulfate (SDS) was used as a catholyte. In this content, SDS $0.05 \mathrm{M}$ was used as catholyte and $\mathrm{Na}_{2} \mathrm{SO}_{4} 0.1 \mathrm{M}$ was used as an anolyte. Low $(1 \mathrm{~V} / \mathrm{cm})$ and high $(2 \mathrm{~V} / \mathrm{cm})$ voltage gradients were used in periodic and continuous forms. The best removal efficiency was observed for high voltage gradient $(2 \mathrm{~V} / \mathrm{cm})$ in a periodic form, which was 63.86. This result showed that a combination of periodic voltage application in addition to the employment of SDS is an effective method for hydrocarbon removal from low permeable sand.
\end{abstract}

Keywords: Continuous, Electrokinetic remediation, Hydrocarbon, Periodic, SDS, Silty sand

\section{Introduction}

Soil pollution is one of the important concerns for environmental engineers all over the world. Several contaminations such as heavy metals, radionuclides, and organic matters exist in the environment Among them, hydrocarbon contaminations are one of the important pollutants in the world. Oil production and the petrochemical industry are one of the main industrial activities responsible for serious environmental pollution. Besides, oil extraction itself is of the most contaminating processes [1].

Soil remediation is a difficult issue due to several factors such as the chemical composition of soil, nature of contaminants, the interaction of contaminants, soil aging of contaminants to name but a few [2]. Different methods have been introduced to remediate polluted soils such as 1-bioremediation, 2-thermal remediation, 3-soil vapor extraction, 4-soil washing, 5-soil flushing, 6-electrokinetic remediation (EKR) [3]. The EKR method has major advantages among the rest: 1-flexibility to use as ex-situ or in-situ methods, 2- applicability to low-permeability and heterogeneous soils, 3applicability to saturated and unsaturated soils, 4-applicability for heavy metals, radionuclides, and organic contaminant. The principle of EKR relies on the application of a low-intensity direct current through a soil specimen between a couple of electrodes (cathode and anode). During the EKR treatment, the applied current causes oxidation and reduction at the anode and cathode, respectively. Therefore, it leads to a series of coupled transport phenomena such as electro-migration, electroosmotic flow (EOF), and electrophoresis [4]. Due to the low water solubility of the most common organic contaminants and the neutrality of their molecules, it is not possible to transport the hydrophobic organics out of the soil by electro-migration and/or EOF [5]. Surfactants and cosolvents have been used to enhance remediation process of hydrocarbon contaminated soils. Han et al. [6] studied on the effect of a chelating agent Ethylenediaminetetraacetic acid (EDTA), a cosolvent (n-propanol), and non-ionic surfactants (Tergitol 15-S-7 and Tergitol NP-10) as additives in the purging solution for EKR of polluted soil. They concluded that the addition of surfactant with EDTA was not effective for diesel oil removal. Tsai et al. [7] evaluated the efficiency of EKR by applying different electrode materials and electrolytes. They reported that Electrokinetically
This is an Open Access article distributed under the terms of the Creative Commons Attribution Non-Commercial License (http://creativecommons.org/licenses/by-nc/3.0/) which permits unrestricted non-commercial use, distribution, and reproduction in any medium, provided the original work is properly cited.

Copyright (C) 2019 Korean Society of Environmental Engineers
Received August 20, 2018 Accepted November 2, 2018

${ }^{\dagger}$ Corresponding author

Email: fardi@khu.ac.ir

Tel: +98-9121192424 Fax: +98-21-88830891

ORCID: 0000-0002-7867-8757 
enhanced oxidation with the presence of both $\mathrm{H}_{2} \mathrm{O}_{2}$ and $\mathrm{Fe}_{3} \mathrm{O}_{4}$ (iron electrode corrosion), itself, resulted in higher total petroleum hydrocarbon removal efficiency (97\%) compared to the efficiencies observed from electrokinetic (55\%) or Fenton oxidation (27\%).

Gonzini et al. [8] investigated the removal of gas oil from a soil using electrokinetic technique enhanced by rhamnolipid. Their results indicated that by an increase in the amount of rhamnolipid, the efficiency of gas oil removal increased up to $86.7 \%$. Ammami et al. [9] studied heavy metals and polycyclic aromatic hydrocarbons (PAHs) removal from dredged harbor sediment using the electrokinetic technique. They stated that application of a periodic voltage gradient associated to a low concentration of citric acid and Tween 20 provided the best results for $\mathrm{Zn}, \mathrm{Cd}$, and $\mathrm{Pb}$ remediation and also for removal of the 16 priority PAHs.

Pazos et al. [10] conducted an EKR test on diesel fuel contaminated soil. They used citric acid to enhance EOF and they performed their tests under $1 \mathrm{~V} \mathrm{~cm}^{-1}$ and $2 \mathrm{~V} \mathrm{~cm}^{-1}$. Their results showed that more powerful electric fields had better pollutant removal. Ranjan et al. [11] carried out water-flushing and surfactant flushing coupled with/without electrokinetic treatments for remediation of diesel fuel contaminated clay. They declared water-flushing coupled with EKR slightly improved the removal efficiency. Boulakradeche et al. [1] performed a set of EKR tests to understand the feasibility of usage of different surfactants to remediate hydrophobic organic contamination. They maintained that the anionic surfactant (SDS) in the catholyte yielded promising remediation results for large-scale application. Moreover, they uttered that a combination of SDS in the catholyte and Tween 80 in the anolyte improved the remediation results. Cameselle and Reddy [2] investigated the simultaneous removal of nickel and phenanthrene from kaolinite as a low permeable soil by periodic voltage gradient. Based on the experimental results, they concluded that the combination of chemical oxidation and EKR was effective for the simultaneous removal of phenanthrene and nickel. Likewise, different experimental studies have been carried out on the feasibility of the EKR for organic and heavy metals contaminated soils enhanced by surfactants and cosolvents including Saichek and Reddy [12], Hahladakis et al. [13], Lin et al. [14], and Song et al. [15].

Although Pazos et al. [10] and Gonzini et al. [8] conducted experimental tests on EKR of low permeable sands, they did not investigate the effect of periodic voltage application on removal efficiency, electric current, and energy expenditure. Moreover, Gonzini et al. [8] and Pazos et al. [10] conducted their test under at least $15 \mathrm{~d}$. In the present study, the remediation of diesel-contaminated silty sand by electrokinetic method was investigated in shorter time. For the purpose of enhancement, SDS $(0.05 \mathrm{M}$ solution) was used at the cathode compartment to improve solubility of hydrophobic organic compounds. $\mathrm{Na}_{2} \mathrm{SO}_{4}(0.1 \mathrm{M})$ was used at the anode compartment in the experiments. The experiments were carried out under continuous and periodic voltage application to understand its effect on the remediation process. The tests were conducted under low $\left(1 \mathrm{~V} \mathrm{~cm}^{-1}\right)$ and high $(2 \mathrm{~V}$ $\mathrm{cm}^{-1}$ ) electric field. The tests were carried out for 7 and $9 \mathrm{~d}$ of treatment to understand the feasibility of the enhanced proposed test in low duration time.

\section{Materials and Methods}

\subsection{Soil Sample Preparation}

In the present study silty sand was used to conduct electrokinetic remediation tests. Silty sand has a low hydraulic permeability and other common remediation methods such as soil washing would not be effective to remediate this kind of sand. In addition, studies on the feasibility of EKR on the low permeable sands are rare. Table 1 indicates the characteristic of the soil used in the present study.

Table 1. Properties of the Soil

\begin{tabular}{lc}
\hline Parameter & Value \\
\hline Grain size distribution & \\
Sand & $80 \%$ \\
Silt & $17 \%$ \\
Clay & $3 \%$ \\
\hline Mineralogy & \\
Quartz & $34 \%$ \\
Feldspar & $33 \%$ \\
Gypsum & $1 \%$ \\
Calcite & $3 \%$ \\
Semitic & $3 \%$ \\
Illite & $2 \%$ \\
Clinoptilolite & $24 \%$ \\
\hline Initial soil pH & 9 \\
\hline Hydraulic permeability & $9.1 \times 10^{-5}\left(\mathrm{~cm} \mathrm{~s}^{-1}\right)$ \\
\hline
\end{tabular}

Diesel was selected as a contaminant because Iran is one of the main oil producers in the world and also a consumer of oil products. Therefore, soil pollution by diesel is highly likely to occur. The soil was polluted artificially to gain 20,000 ppm initial concentrations. According to the water holding capacity of soil, $100 \mathrm{~mL}$ diesel fuel was added with a mixture with water to 5,000 $\mathrm{g}$ of soil to achieve $20,000 \mathrm{mg}$ of pollutant per $\mathrm{kg}$ of soil. The contaminated sample was stirred and blended to achieve homogeneous mixture. The soil sample was kept at room temperature $\left(2^{\circ} \mathrm{C}\right)$ for two weeks until water evaporates. After contamination to reassure initial concentration of diesel, 200 grams of contaminated soil were taken for concentration analysis.

\subsection{Electrokinetic Setup}

The electrokinetic setup consisted of different parts; soil cell, two electrode compartments (anode and cathode), anode and cathode reservoirs, peristaltic pumps to circulate the solution, a power supply, multimeter to measure the current passing through the soil. The electrokinetic cell was made of Plexiglas. As indicated in Fig. 1, the cell is a rectangular cube with the dimensions of $30 \times 5 \times 5 \mathrm{~cm}$ and is made of $5 \mathrm{~mm}$ thick transparent Plexiglas. The dimensions of each anode and cathode compartments are $7 \times 5 \times 5 \mathrm{~cm}$ with $175 \mathrm{~mm}^{3}$ volumes and during the tests the 


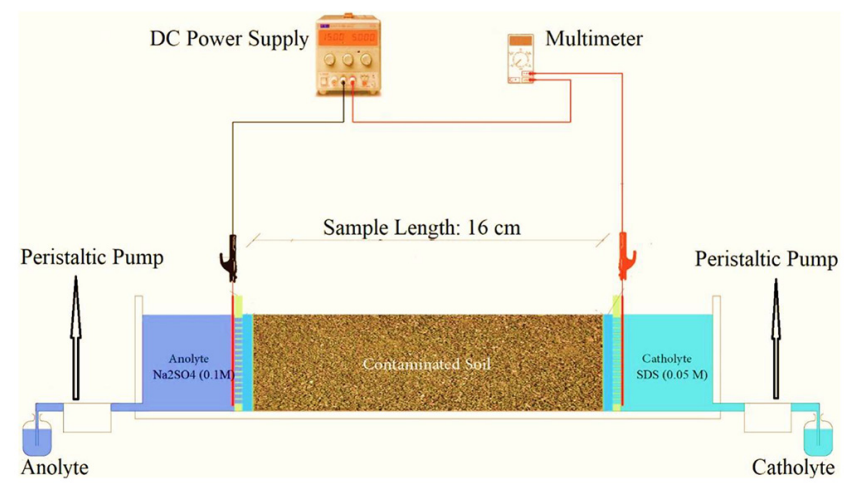

Fig. 1. The schematic of the electrokinetic pilot test.

level of anolyte and catholyte were kept constant to prevent hydraulic head in the tests. The dimensions of the soil cell were $16 \times$ $5 \times 5 \mathrm{~cm}$ with a volume of $400 \mathrm{~cm}^{3}$, the anode and cathode cells are separated from the soil cell with the help of two $5 \mathrm{~mm}$ thick mesh separators. Between the soil sample and separators, a porous stone with dimensions of $5 \times 5 \times 0.5 \mathrm{~cm}$ plus Whatman filter paper No. 41 was used to prevent the separation of soil grains and entry into the anode or cathode cell. The graphite electrode was used in the experiments. The dimensions of the plate electrode were $55 \times 40 \times 0.1 \mathrm{~mm}$. The DC power supply had the potential to produce an electric potential difference of up to $40 \mathrm{~V}$. The intensity of the current produced by this device was limited to $3,000 \mathrm{~mA}$. The tests were conducted under constant voltage drop, so the multimeter showed the current passing through the soil sample.

\subsection{Testing Procedure}

For each test, the artificially contaminated soil was packed to the soil cell. The anode compartment was filled with $\mathrm{Na}_{2} \mathrm{SO}_{4} 0.1$ $\mathrm{M}$ solution. In soil remediation, the surfactants concentration should be above the critical micelle concentration (CMC) to solubilize the contaminants and minimize their resorption on soil particles [16]. Consequently, a concentration equal to 0.05 $\mathrm{M}$ for SDS solution was used which was above CMC at the cathode compartment. Constant voltage gradient was applied to the soil sample. Following that, four tests were carried out and the name of each test was tabulated in Table 2. For EK1 and EK2, voltage gradient equal to $1 \mathrm{~V} / \mathrm{cm}$ was applied and for EK3 and EK4, the voltage gradient equal to $2 \mathrm{~V} / \mathrm{cm}$ was applied to the soil sample. Two different procedures, periodic and continuous, were utilized for voltage application. For EK1 and EK3 continuous voltage gradient for $7 \mathrm{~d}$ was applied to the soil sample. For EK2 and EK4 periodic voltage application was applied. In the periodic form of voltage application, the voltage was applied for $5 \mathrm{~d}$ and the power supply was switched off for $2 \mathrm{~d}$ and then was switched on for $2 \mathrm{~d}$. The main reason to switch off and on the power supply is to understand its effect on the remediation process and solubilizing the complexes. Table 2 shows the experimental work plan in the present study.

\subsection{Analytical Procedure}

The soil $\mathrm{pH}$ was measured before and after treatment for each sample. For $\mathrm{pH}$ measurement, 1:2.5 soils to deionized water slurry were prepared and agitated by a wrist action shaker for $30 \mathrm{~min}$, after that the soil sample centrifuged for $15 \mathrm{~min}$ at 6,000 RPM and $\mathrm{pH}$ determined in the supernatant. The $\mathrm{pH}$ of anolyte and catholyte measured before, during, and after the treatment by directly immersing $\mathrm{pH}$. The soil specimens were sectioned into four different parts after the remediation process. Two samples were prepared for each section, one for $\mathrm{pH}$ and another for hydrocarbon concentration analysis. Each sample preserved in a separate glass jar. Soxhlet extraction method was used for hydrocarbon extraction from soil materials based on USEPA test method 6540C [17] then for chemical analysis the gas chromatography was used. Since the experiments were carried out by applying a constant voltage drop during the test, the current intensity varied with the porous medium resistivity, which was measured using a digital multimeter manufactured by Ziegler in Germany with a precision of 0.01 $\mathrm{mA}$. Due to the direct current (DC) applied to the cell, the multimeter connected in series with the power supply to the cell, so that the number displayed on the device is the amount of current passing through the soil (Fig. 1).

\section{Results and Discussion}

\subsection{Electrolyte and Soil pH}

The electrolysis reaction takes place at anode and cathode cells due to applying an electric field; therefore, hydrogen and hydroxide ions are generated at anode and cathode compartments, respectively. SDS solution has no buffering capacity, so $\mathrm{pH}$ inside the cathode cell increased rapidly. Likewise, sodium sulfate solution at the anode cell has no buffering capacity and $\mathrm{pH}$ at the anode compartment decreased rapidly. The hydrogen and hydroxide generation caused extreme $\mathrm{pH}$ changes at anode and cathode compartments. Fig. 2 illustrates $\mathrm{pH}$ changes at the anode and cathode compartments. $\mathrm{pH}$ of the anode cell decreased due to hydrogen generation, the $\mathrm{pH}$ decreased to the point around 3 after

Table 2. Experimental Work Plan

\begin{tabular}{|c|c|c|c|c|c|c|}
\hline No. & Test's code & $\begin{array}{l}\text { Purging solution at } \\
\text { anode compartment }\end{array}$ & $\begin{array}{l}\text { Purging solution at } \\
\text { cathode compartment }\end{array}$ & Voltage gradient & $\begin{array}{l}\text { Mode of the } \\
\text { electric field }\end{array}$ & $\begin{array}{l}\text { Remediation } \\
\text { duration (day) }\end{array}$ \\
\hline 1 & EK1 & $10^{-1} \mathrm{M} \mathrm{Na}_{2} \mathrm{SO}_{4}$ & $5 \times 10^{-2} \mathrm{M}$ SDS & $1 \mathrm{~V} / \mathrm{cm}$ & Continuously & 7 \\
\hline 2 & EK2 & $10^{-1} \mathrm{M} \mathrm{Na}_{2} \mathrm{SO}_{4}$ & $5 \times 10^{-2} \mathrm{M}$ SDS & $1 \mathrm{~V} / \mathrm{cm}$ & Periodic & 9 \\
\hline 3 & EK3 & $10^{-1} \mathrm{M} \mathrm{Na}_{2} \mathrm{SO}_{4}$ & $5 \times 10^{-2} \mathrm{M}$ SDS & $2 \mathrm{~V} / \mathrm{cm}$ & Continuously & 7 \\
\hline 4 & EK4 & $10^{-1} \mathrm{M} \mathrm{Na}_{2} \mathrm{SO}_{4}$ & $5 \times 10^{-2} \mathrm{M}$ SDS & $2 \mathrm{~V} / \mathrm{cm}$ & Periodic & 9 \\
\hline
\end{tabular}




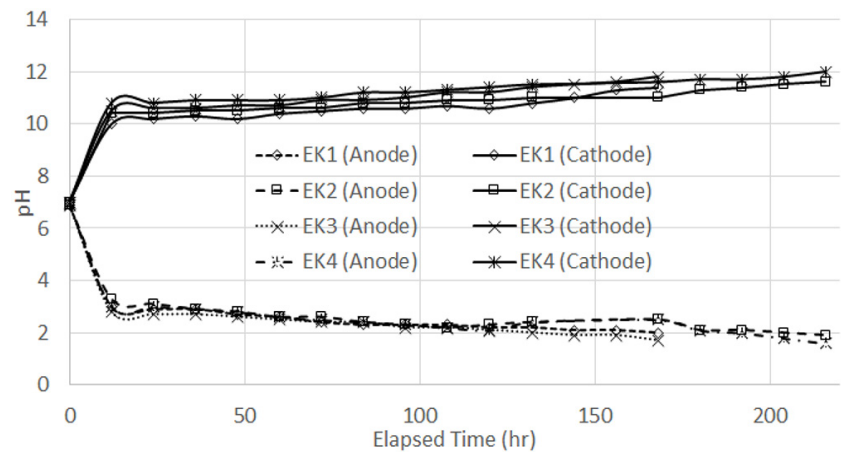

Fig. 2. $\mathrm{pH}$ changes in anode and cathode cells during EKR tests.

$12 \mathrm{~h}$ and decreased to 2 at the end of the tests. On account of hydroxide generation, $\mathrm{pH}$ on the cathode increased and $\mathrm{pH}$ of the cathode cell after $12 \mathrm{~h}$ reached around 11 and increased up to 12 at the end of the experiments. The results are consistent with the output of other researchers $[8,18,19]$.

Fig. 3 shows soil $\mathrm{pH}$ at the end of the tests. The soil $\mathrm{pH}$ was modified by penetration of acid and base front. The hydrogen and hydroxide ion transport into the soil medium by electro-migration toward cathode and anode, respectively. The acid and base front changed soil $\mathrm{pH}$, so sections close to the anode cell got acidified because of high concentration of hydrogen ions and sections close to the cathode cell got alkaline because of high concentration of hydroxide [1, 20]. The rate of hydrogen transportation is higher than hydroxide transportation, because the ionic mobility of the hydrogen is higher than the ionic mobility of the hydroxide, moreover the EOF direction is from the anode to the cathode compartment. As it is observed in Fig. 3, at the end of the tests, sections 1 and 2 from the anode got acidified and section 3 from the anode had a $\mathrm{pH}$ around to initial value of the soil $\mathrm{pH}$. This phenomenon is due to the fact that the transportation of acid front is higher than the base front and by continuing the EKR test the section close to the cathode cell might get modified by the presence of hydrogen ions.

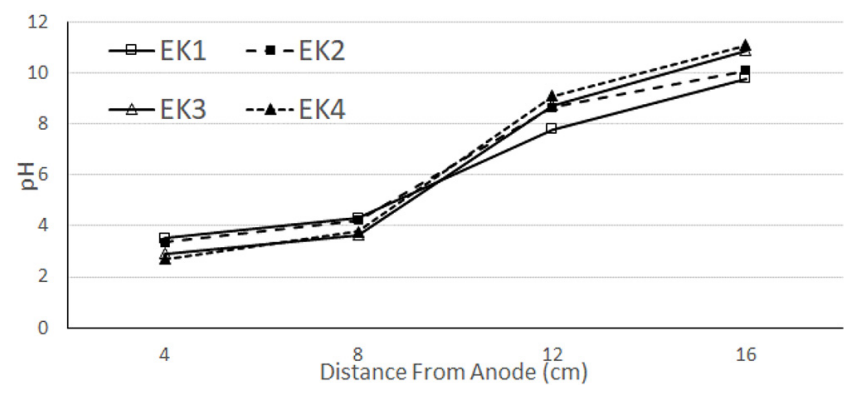

Fig. 3. $\mathrm{pH}$ changes in the soil specimen at the end of the tests.

\subsection{Electric Current}

Fig. 4 indicates the electric current passing through the soil specimen. The presence of the solubilized charged complexes and ions in the pore fluid can effect on the conductivity of the medium. By increasing the concentration of the solubilized charged complexes and ions in the pore fluid the conductivity increases, and by increasing the conductivity the electrical resistivity decreases.

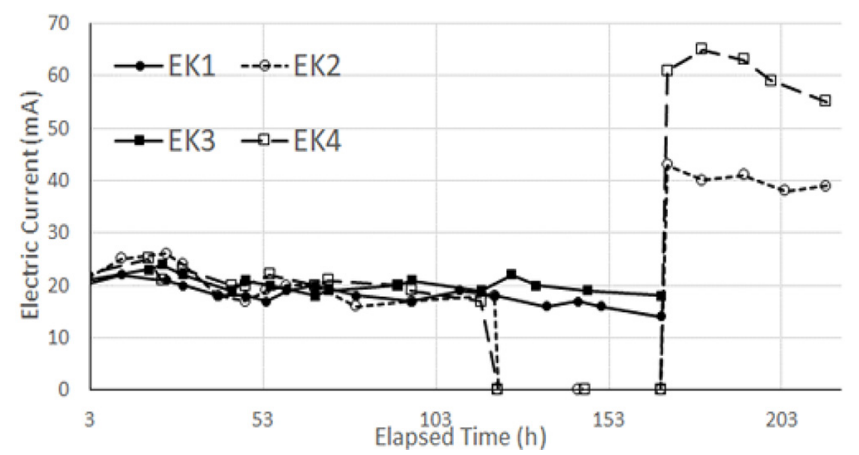

Fig. 4. Electric current through the soil sample during the EKR tests.

The amount of current depends on the resistivity of the medium and when resistivity increases current decreases and vice versa. Therefore, the electric current is the response to the charge transportation from the anode and cathode. As illustrated in Fig. 4, the amount of current increased for $1 \mathrm{~d}$ in all the experiments and after that current reached approximately constant value. The initial increase in electric current caused by the solubilization of salt precipitates [21]. Yet, by running the tests the ions are transported by electro-migration and current intensity decreased to stabilize current values [22]. According to Fig. 4, the current fluctuation is observable for EK2 and EK4 when the periodic voltage was applied to the soil medium. When the power supply was switched off for two days, it allowed time for mass transfer of charged solutes from soil to the aqueous medium [5]; therefore, causing a higher electric current when the voltage was applied after two days. Consequently, periodic voltage application resulted in an up-and-down pattern of electric current.

\subsection{Diesel Removal}

Surfactants increase the aqueous solubility of oil by reducing the surface/interfacial tension at air-water and water-oil interfaces. By reduction of interfacial tension, the aqueous surfactant concentration increased, and the monomers aggregated to form micelles [16]. CMC is the surfactant concentration at which micelles first begin to form. Mobilization and solubilization are two ways that surfactants enhance the removal of oil from soils. Under the surfactant's CMC the mobilization mechanism occurs. Interfacial tension between air/water, oil/water, and soil/water systems are reduced by the surfactant. Surfactants increase the contact angle and reduce the capillary force between oil and soil by means of reduction of the interfacial force. Above the surfactants' CMC the accumulation of surfactant micelles increases the solubility of oil [16]. For the purpose of soil remediation, the surfactants concentration should be above the CMC to solubilize the contaminants and minimize their resorption on soil particles [16].

SDS introduced in the cathode cell and can transport into the soil medium by electro-migration toward the anode. SDS and hydrophobic organic compounds form negatively charged micelles in the medium. Negatively charged micelles are under the effect of electrophoresis and EOF. EOF direction is from the anode to the cathode and electrophoresis transports negatively charged micelles to the anode. Therefore, the direction of EOF and electrophoresis oppose each other which might reduce the remediation 
efficiency. This would be disadvantageous of using an SDS, yet the usage of cationic and neutral surfactant has their disadvantage. Cationic surfactant creates positive micelles by hydrophobic organic compound and the direction of the EOF and electrophoresis is the same (from the anode to the cathode). However, the point is that cationic surfactant can easily be adsorbed to the surface of the soil particles. Moreover, based on the work of Kaya and Yukselen [23] by increasing the concentration of cationic surfactant zeta potential increases (gets less negative) and at a specific concentration of cationic surfactant, zeta potential gets positive which results in reverse EOF. Reverse EOF (from the cathode to the anode) opposes electrophoretic mobility of positively charged micelles. The neutral surfactant would be a good option to use instead of anionic surfactant, but according to the work of Kaya and Yukselen [23], the presence of non-ionic surfactant might decrease the EOF which is the main transport phenomenon for organic compounds [24]. In addition, lower dielectric constant and higher viscosity than water, resulting in a reduction in the EOF by using non-ionic surfactant [25]. Eq. (1) shows the volumetric EOF rate based on Helmholtz-Smoluchowski expression, EOF depends on different parameters such as porosity, the permittivity of the medium, the viscosity of fluid, and zeta potential [20]. The presence of surfactant can increase the viscosity of the fluid and increase the resistance of the fluid to flow [1]. Although the presence of the SDS as a surfactant increase fluid's resistivity, SDS can increase the EOF by decreasing zeta potential (makes zeta potential more negative) [23]. Therefore, in the present study, SDS was used as an enhancement.

$$
q_{e o}=n A \frac{D \zeta}{\eta} E_{z}
$$

where $n$ is porosity, $A$ is cross-section area of soil, $\zeta$ is zeta potential, $D$ is the dielectric constant of the fluid, $\eta$ is the viscosity of the fluid, $E_{z}$ applied voltage gradient.

Fig. 5 illustrates total petroleum hydrocarbon-diesel after EKR tests. As indicated in Fig. 5 the tests' results show that the EKR was effective in removing diesel from the soil. EOF equal to 37 $\mathrm{mL} \mathrm{d}^{-1}$ and $40 \mathrm{~mL} \mathrm{~d}^{-1}$ was measured for EK1 and EK2, respectively. Higher EOF rate was measured for EK2 than EK1 which means that periodic voltage application can improve and increase EOF, this phenomenon was observed by other researchers [9]. According to Fig. 5, EK1 and EK2 had the average removal equal to 52.48 and 57.6 percent, respectively. The removal efficiency of hydrophobic organic compounds depends on two important factors: 1- dissolution of the contaminant by surfactant 2- EOF. EK 2 has higher EOF than EK1 and during the "down" time of periodic voltage application, re-equilibrium at the solid-liquid interface occurs and more organic compounds can be solubilized into micellar aggregates [9].

EK3 and EK4 were conducted under $2 \mathrm{~V} \mathrm{~cm}^{-1}$ electric field. EOF rate equal to $42 \mathrm{~mL} \mathrm{~d}^{-1}$ and $46 \mathrm{~mL} \mathrm{~d}^{-1}$ were observed. Likewise, the periodic voltage caused higher EOF rate (EK4 showed higher EOF than EK3). Moreover, the tests conducted under $2 \mathrm{~V} / \mathrm{cm}$ voltage gradient showed higher EOF rate which is in agreement with the work of other researchers [10] and based on Eq. (1) it was predictable. Based on Fig. 5, the average removal efficiency equal to 58.62 and 63.86 was calculated for EK3 and EK4, respectively. In the

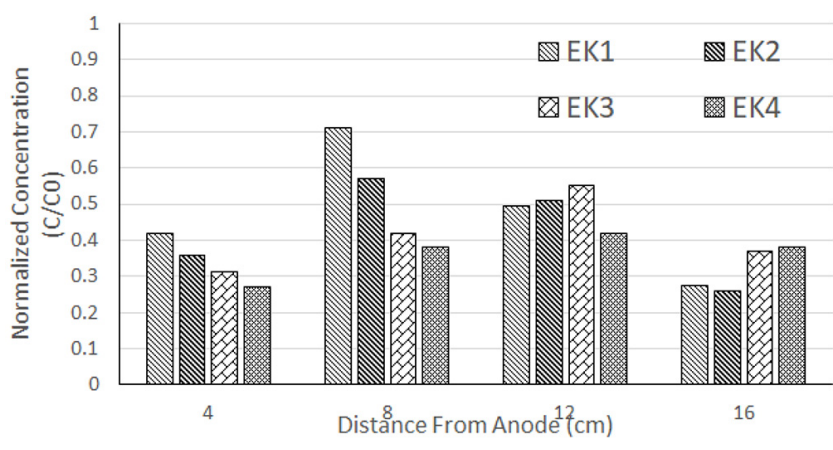

Fig. 5. Total petroleum hydrocarbon-diesel concentration after EKR tests.

same way, higher EOF and solubilization of organic compounds into micellar aggregates result in better removal efficiency of EK4 than EK3. Generally, higher voltage gradient resulted in higher removal efficiency. The flux of colloids and micelles under electrokinetic remediation process can be expressed by Eq. (2).

$$
N_{i}=-D_{i}^{e f f} \nabla c_{i}-\left(U_{i}^{e f f}+k_{e o}\right) c_{i} E_{z}
$$

where $D_{i}^{\text {eff }}$ is the effective diffusion coefficient, $c_{i}$ is molar concentration, $k_{e o}$ is electroosmosis permeability, and $U_{i}^{e f f}$ is effective electrophoretic mobility which calculated based on NernstEinstein relation Eq. (3):

$$
U_{i}^{e f f}=\frac{D_{i}^{e f f} z_{i} F}{R T}
$$

where $z_{i}$ is the ionic charge of the species, $F$ is the Faraday constant, $R$ is the ideal gas constant, and $T$ is the absolute temperature.

Micelles and colloids under electric field transport under the effect of EOF and electrophoretic mobility, so higher voltage gradient can increase EOF and electrophoretic mobility. The cooperation of these transport mechanisms can improve hydrocarbon removal from the soil medium. Consequently, tests under $2 \mathrm{~V} / \mathrm{cm}$ voltage gradient indicated better removal efficiency.

The best removal efficiency was achieved for EK4, two main reasons would be the cause of this result, the first reason is using a high voltage application and the second is considered a periodic voltage application. The EK4 test was conducted for $9 \mathrm{~d}(7 \mathrm{~d}$ applying electric field). It would be possible to achieve better removal efficiency by increasing the time of the test. Because two days switching off the power supply helped more organic compounds solubilized into micellar aggregates. The removal efficiency of EK2 and EK3 were close. Although EK3 showed a bit better removal efficiency due to higher voltage application, its efficiency could not increase by further running the test very much. The electric current passing through the soil for EK3 declined after $7 \mathrm{~d}$. Decreasing the electric current indicated the less charged complex and ions in solubilized form. Therefore, by running the test the removal efficiency might not increase considerably. However, EK2 after two days switching off the power supply, the electric current passing through increased and this issue indicated that by running the test in the following days more removal efficiency could be achieved. Even though EK2 and EK3 tests 
Table 3. Energy Consumption and Average Removal for Each Experiment

\begin{tabular}{lcccc}
\hline Test No. & Test 1 & Test 2 & Test 3 & Test 4 \\
\hline Average removal $(\%)$ & 52.48 & 57.60 & 58.62 & 63.86 \\
Energy consumption $\left(\mathrm{kWh} / \mathrm{m}^{3}\right)$ & 519.1 & 723.2 & $1,151.4$ & $1,810.8$ \\
\hline
\end{tabular}

showed close removal efficiency by means of using a high voltage application for EK2 and periodic voltage application for EK3, by continuing the tests the result could be different.

\subsection{Electrical Energy Expenditure}

Eq. (4) was used in order to calculate electrical energy expenditure for each experiment [4]:

$$
E=\frac{1}{V_{s}} \int V I d t
$$

where $E$ is the electrical energy per unit volume $\left(\mathrm{kWh} / \mathrm{m}^{3}\right), V$ is the imposed external voltage (V), $I$ is the electrical current (mA), $t$ is the experiment duration, and $V_{s}$ is the soil volume $\left(\mathrm{m}^{3}\right)$. The result of energy expenditure calculation is tabulated in Table 3. EK4 was the most energy consuming and resulted in the best removal efficiency among other tests, while the least energy consuming test is EK1. In addition, EK1 showed the lowest removal efficiency. As the electric energy expenditure is a function of electric current passing through the soil, the tests that had higher electric current during the time of the test resulted in more energy expenditure.

\subsection{Comparison Present Study with the Previous Works}

Most of the work used the periodic voltage application were conducted on the clayey soils, mostly kaolinite, yet in the present study, we focused on the remediation of low permeable sand by both continuous and periodic voltage application which has not been investigated yet. The previous studies on the electrokinetic remediation of sandy soil used a continuous form of voltage application and they did not conduct any comparative study on the periodic and continuous voltage application. Moreover, the effect of periodic voltage applied on the electric current passing through the soil, electrical energy expenditure, and hydrocarbon removal were discussed in the present study. In addition, the conducted studies on the electrokinetic remediation of low permeable soil were performed at least for $15 \mathrm{~d}$, but in the present study based on using high voltage applications in periodic form average removal efficiency equal to 63.8 was achieved which is a good removal efficiency just in $9 \mathrm{~d}$. Therefore, even though by decreasing the time of the remediation process, a reasonable and acceptable removal efficiency was yielded. The time of the remediation is a key important factor in the cost of the tests and energy expenditure.

In the present study the studied soil is sand, but this is a silty sand with hydraulic permeability equal to $9.1^{*} 10^{-5}\left(\mathrm{~cm} \mathrm{~s}^{-1}\right)$ which indicate that the soil has a very low hydraulic permeability. For the soils with low hydraulic permeability, soil washing is not an effective way to remediate them. Therefore, an alternative method such as electrokinetic soil remediation could be an effective option.

Song et al. [15] used electrokinetic for diesel removal from sandy soil using $\mathrm{NaCl}$ or $\mathrm{NaNO}_{3}$ with different voltages using continuous voltage application and their results of diesel removal is similar to the present study. The differences are, in our study both continuous and periodic voltages were examined and the remediation was enhanced by a surfactant (sodium dodecyl sulfate, SDS) as a catholyte. And the time of the remediation for diesel removal which is important was $9 \mathrm{~d}$ but Song et al. [15] conducted their test for $15 \mathrm{~d}$.

Gonzini et al. [8] studied the removal of gas oil from sandy clay loam using rhamnolipid as bio surfactant at various rates. They achieved gas oil removal around $39.1 \%$ to $86.7 \%$ after 15 $\mathrm{d}$ of remediation. They used two different voltage intensity (30 and 60) in continuous mode. The difference between the present study and their study is time of remediation, types of soil, type of surfactant. In the present study both continuous and periodic voltages were applied to the soil, $9 \mathrm{~d}$ of remediation, using silty sand and the analyzing the rate of energy consuming.

Jeon et al. [26] investigated the removal of petroleum hydrocarbon from residual clayey following a washing process with 100 to 200 h' time of remediation, using $0.1 \mathrm{M} \mathrm{MgSO}_{4}$ and 0.1 $\mathrm{NaOH}$ with surfactant. They achieved 0 to $39 \%$ removal. Their soil contains $32 \%$ sand and silt and $68 \%$ clay. The difference between the present investigation and their study is the voltage mode application (continuous and periodic); however, they used only continuous voltage and removal efficiency in the present work is higher than total petroleum hydrocarbon removal in their study by using continuous voltage.

Pazos et al. [27] investigated the diesel removal from loamy sand using two different hybrid approaches, including adding surfactant and in the second method combining Fenton reaction and electrokinetic remediation. In the first hybrid method, they used $3 \%$ Tween 80 and Tris-Acetate-EDTA $0.2 \mathrm{M} \mathrm{pH} 8.5$ as pH control, continuous current $(3 \mathrm{~V} / \mathrm{cm})$ and $30 \mathrm{~d}$ of remediation. With this condition 55\% diesel was removed from the soil. However, while using Fenton reaction and electrokinetic their removal reached to $87 \%$. The present study can be compared with the first hybrid approach. In the present study maximum removal efficiency about $64 \%$ was achieved after $9 \mathrm{~d}$ (time of remediation) and under 2 $\mathrm{V} / \mathrm{cm}$ electric field and using periodic voltage.

\section{Conclusions}

The key results of the experimental study for the diesel removal of silty sand using electrokinetic technique are as follows:

i ) The use of SDS as a solution in the cathode compartment was effective in the experiments to solubilize hydrophobic organic compounds and increase removal efficiency.

ii ) Applying periodic voltage gradient caused to increase the electric current passing through the soil. When the power supply was switched off for two days, it allowed time for 
mass transfer of charge solutes from the soil to the aqueous medium which is the cause of the electric current increase.

iii) Comparing the results of the tests indicated that applying a voltage in periodic form can be an effective method to increase EKR performance because of increasing EOF and mass transfer of charged solutes from the soil to the aqueous medium.

iv) According to the observed removal efficiency of the tests, increasing the voltage gradient is an effective method to increase EKR efficiency.

v ) The best removal efficiency was observed for EK4. The result showed that a combination of high voltage application in periodic form can be an efficient procedure to enhance EKR method.

vi) The calculation of electric energy expenditure indicated that the tests that had higher electric current during the time of the test showed higher energy expenditure. In addition, energy expenditure is a function of voltage intensity. EK4 illustrated the most energy consuming tests and the most effective test among other.

\section{References}

1. Boulakradeche MO, Akretche DE, Cameselle C, Hamidi N. Enhanced electrokinetic remediation of hydrophobic organics ontaminated soils by the combinations of non-ionic and ionic surfactants. Electrochim. Acta 2015;174:1057-1066.

2. Cameselle C, Reddy KR. Effects of periodic electric potential and electrolyte recirculation on electrochemical remediation of contaminant mixtures in clayey soils. Water Air Soil Pollut. 2013;224:1636.

3. Virkutyte J, Sillanpää M, Latostenmaa P. Electrokinetic soil remediation - Critical overview. Sci. Total Environ. 2002;289: 97-121.

4. Reddy KR, Chinthamreddy S. Sequentially enhanced electrokinetic remediation of heavy metals in low buffering clayey soils. J. Geotech. Geoenviron. Eng. 2003;129:263-277.

5. Maturi K, Reddy KR, Cameselle C. Surfactant-enhanced electrokinetic remediation of mixed contamination in low permeability soil. Sep. Sci. Technol. 2009;44:2385-2409.

6. Han H, Lee Y, Kim S. Electrokinetic remediation of soil contaminated with diesel oil using EDTA - Cosolvent solutions. Sep. Sci. Technol. 2009;44:2437-2454.

7. Tsai TT, Sah J, Kao CM. Application of iron electrode corrosion enhanced electrokinetic-Fenton oxidation to remediate diesel contaminated soils: A laboratory feasibility study. J. Hydrol. 2010;380:4-13.

8. Gonzini O, Plaza A, Di Palma L, Lobo MC. Electrokinetic remediation of gasoil contaminated soil enhanced by rhamnolipid. J. Appl. Electrochem. 2010;40:1239-1248.

9. Ammami MT, Portet-Koltalo F, Benamar A, Duclairoir-Poc C, Wang H, Le Derf F. Application of biosurfactants and periodic voltage gradient for enhanced electrokinetic remediation of metals and PAHs in dredged marine sediments. Chemosphere 2016;125:1-8.

10. Pazos M, Plaza A, Martín M, Lobo MC. The impact of electro- kinetic treatment on a loamy-sand soil properties. Chem. Eng. J. 2012;183:231-237.

11. Ranjan RS, Qian Y, Krishnapillai M. Effects of electrokinetics and cationic surfactant cetyltrimethylammonium bromide [CTAB] on the hydrocarbon removal and retention from contaminated soils. Environ. Technol. 2006;27:767-776.

12. Saichek RE, Reddy KR. Surfactant-enhanced electrokinetic remediation of polycyclic aromatic hydrocarbons in heterogeneous subsurface environments. J. Environ. Eng. Sci. 2005;4: 327-339.

13. Hahladakis JN, Latsos A, Gidarakos E. Performance of electroremediation in real contaminated sediments using a big cell, periodic voltage and innovative surfactants. J. Hazard. Mater. 2016;320:376-385.

14. Lin W, Guo C, Zhang H, et al. Electrokinetic-enhanced remediation of phenanthrene-contaminated soil combined with Sphingomonas sp. GY2B and biosurfactant. Appl. Biochem. Biotechnol. 2016;178:1325-1338.

15. Song Y, Cang L, Fang G, Ata-Ul-Karim ST, Xu H, Zhou D. Electrokinetic delivery of anodic in situ generated active chlorine to remediate diesel-contaminated sand. Chem. Eng. J. 2018;337:499-505.

16. Vreysen S, Maes A. Remediation of a diesel contaminated, sandy-loam soil using low concentrated surfactant solutions (5 pp). J. Soil. Sediment. 2005;5:240-244.

17. USEPA. Sohxlet Extraction, Method 3540C. 1996. p. 1-8.

18. Asadollahfardi G, Nasrollahi M, Rezaee M, Khodadadi Darban A. Nickel removal from low permeable kaolin soil under unenhanced and EDTA-enhanced electrokinetic process. Adv. Environ. Res. 2017;6:147-158.

19. Giannis A, Gidarakos E, Skouta A. Application of sodium dodecyl sulfate and humic acid as surfactants on electrokinetic remediation of cadmium-contaminated soil. Desalination 2007;211:249-260.

20. Asadollahfardi G, Rezaee M, Tavakoli Mehrjardi G. Simulation of unenhanced electrokinetic process for lead removal from kaolinite clay. Int. J. Civ. Eng. 2016;14:263-270.

21. Mitchell JK. Fundamentals of soil behavior. Wiley; 1993.

22. Maturi K, Reddy KR. Simultaneous removal of organic compounds and heavy metals from soils by electrokinetic remediation with a modified cyclodextrin. Chemosphere 2006;63: 1022-1031.

23. Kaya A, Yukselen Y. Zeta potential of soils with surfactants and its relevance to electrokinetic remediation. J. Hazard. Mater. 2005;120:119-126.

24. Reddy KR, Cameselle C. Electrochemical remediation technologies for polluted soils, sediments and groundwater. Wily; 2009.

25. Cameselle C, Reddy KR. Development and enhancement of electro-osmotic flow for the removal of contaminants from soils. Electrochim. Acta 2012;86:10-22.

26. Jeon C-S, Yang J-S, Kim K-J, Baek K. Electrokinetic removal of petroleum hydrocarbon from residual clayey soil following a washing process. Clean Soil Air Water 2010;38:189-193.

27. Pazoz M, Alcntara MT, Rosales E, Sanroman MA. Hybrid technology for remediation of diesel fuel polluted soil. Chem. Eng. Technol. 2011;34:2077-2082. 